\title{
Relevance of Modified Debridement-Irrigation, Antibiotic Therapy and Implant Retention Protocol for the Management of Surgical Site Infections: A Series of 1694 Instrumented Spinal Surgery
}

\author{
Romain Manet ${ }^{1,2}$, Tristan Ferry 3,4,5,6, Jean-Etienne Castelain7, Gilda Pardey Bracho8, Eurico Freitas-Olim7 ,
} Jacqueline Grando ${ }^{9}$, Cédric Barrey ${ }^{4,5,7,10}$

1. Department of Neurosurgery B, Hôpital Pierre Wertheimer, Hospices Civils de Lyon, Lyon, France

2. Department of Neurosurgery, Clinique Mutualiste Chirurgicale, Saint-Etienne, France

3. Department of Infectious Diseases, Hôpital de la Croix-Rousse, Hospices Civils de Lyon, Lyon, France

4. University Claude Bernard Lyon 1, Lyon, France

5. Regional reference center for complex bone and joint infections (CRIOAc Lyon), Hospices Civils de Lyon, France

6. International research center in infectiology, CIRI, Inserm U1111, CNRS UMR5308, ENS de Lyon, UCBL1, Lyon, France

7. Department of Spine Surgery, Hôpital Pierre Wertheimer, Hospices Civils de Lyon, Lyon, France

8. Department of Anesthesiology, Hôpital Pierre Wertheimer, Hospices Civils de Lyon, Lyon, France

9. Department of Infectious Diseases Prevention, Hôpital Pierre Wertheimer, Hospices Civils de Lyon, Lyon, France

10. Laboratory of Biomechanics, Arts et Metiers Paristech, Paris, France

$\triangle$ Corresponding author: Romain Manet, Department of Neurosurgery B, Hôpital Pierre Wertheimer, Hospices Civils de Lyon, 59 Bd Pinel, 69677, Lyon Cedex, France. Tel: +33472357495; Fax: +33472119077; Mail: romain.manet@neurochirurgie.fr

(C) Ivyspring International Publisher. This is an open access article distributed under the terms of the Creative Commons Attribution (CC BY-NC) license (https://creativecommons.org/licenses/by-nc/4.0/). See http://ivyspring.com/terms for full terms and conditions.

Received: 2018.07.25; Accepted: 2018.10.29; Published: 2018.12.24

\begin{abstract}
Introduction: Management of surgical site infections (SSI) after instrumented spinal surgery remains controversial. The debridement-irrigation, antibiotic therapy and implant retention protocol (DAIR protocol) is safe and effective to treat deep SSI occurring within the 3 months after instrumented spinal surgery.

Methods: This retrospective study describes the outcomes of patients treated over a period of 42 months for deep SSI after instrumented spinal surgery according to a modified DAIR protocol.

Results: Among 1694 instrumented surgical procedures, deep SSI occurred in 46 patients (2.7\%): 41 patients (89\%) experienced early SSI (< 1 month), 3 (7\%) delayed SSI (from 1 to 3 months), and 2 (4\%) late SSI (> 3months). A total of 37 patients had a minimum 1 year of follow-up; among these the modified DAIR protocol was effective in 28 patients (76\%) and failed (need for new surgery for persistent signs of SSI beyond 7 days) in 9 patients (24\%). Early second-look surgery ( $\leq 7$ days) for iterative debridement was performed in 3 patients, who were included in the cured group. Among the 9 patients in whom the modified DAIR protocol failed, none had early second-look surgery; 3 (33\%) recovered and were cured at 1 year follow-up, and 6 (66\%) relapsed. Overall, among patients with SSI and a minimum 1 year follow-up, the modified DAIR protocol led to healing in $31 / 37$ (84\%) patients.

Conclusions: The present study supports the effectiveness of a modified DAIR protocol in deep SSI occurring within the 3 months after instrumented spinal surgery. An early second-look surgery for iterative debridement could increase the success rate of this treatment.
\end{abstract}

Key words: risk factors, spinal surgery, surgical site infection, surgical wound infection

\section{Introduction}

Surgical site infection (SSI) is an infrequent complication after instrumented spinal surgery. It, however, remains an important concern as it can potentially lead to iterative surgery, prolonged hospital stay, and additional costs, but also may result in major morbidity. Overall, SSI occurs in 1 to $17 \%$ of 
cases [1,2], and in complex instrumented spine procedures this rate is reported to reach 3 to $20 \%$ [3]; late-onset infections occur in $1.7-2.7 \%$ [2,4]. Risk factors for infection after spinal surgery include host-related risk factors (age, obesity, diabetes, smoking) and procedure-related risk factors (posterior approach, fusion, number of levels fused, presence of instrumentation, duration $>3$ hours, importance of blood loss, postoperative drainage $>3$ days) [5].

In the absence of robust data, no standardized guideline has been published concerning the management of SSI after instrumented spinal surgery. However, there is no evidence to suggest that spinal instrumentation retention inhibits the ability to treat early-onset postoperative spinal infection [6]. A protocol including surgical debridement-irrigation (that decreases the bacterial inoculum and allows pathogen identification), intravenous combination antibiotic therapy, and implant retention (DAIR protocol) for deep infections of instrumented spine patients has been proposed. Indeed, spinal bone structures are highly vascularized, allowing good penetration and diffusion of antibiotics [7]. This is accepted only for early-onset infections (occurring within 30 days of the index surgery), as proposed for prosthetic joint infection [8]; for late-onset infections (>3 months) removal of instrumentation is required in most cases, especially to eradicate biofilm-embedded pathogens, but this is associated with a high risk of mechanical failure if fusion is incomplete. In delayed infections (between 1 and 3 months), there is no consensus but encouraging results have been reported for management using the DAIR protocol $[9,10]$.

The present study aimed at describing the outcomes of patients treated according to a modified DAIR protocol for early-onset and delayed post-operative spinal SSI (occurring within the 3 months after index surgery), and identify risk factors for relapse.

\section{Methods}

This observational retrospective cohort study, based on prospectively collected data, was conducted in patients who underwent spinal surgery over a period of 3 years and 6 months (between April 19, 2011 and October 13, 2014), in the spine unit of the neurological hospital of the university hospitals of Lyon, France, which is specialized in deformity and complex spine surgery. This center belongs to the regional reference center for the management of complex bone and joint infections (CRIOAc Lyon) [11].

In our institution, SSI prevention follows national and international guidelines for preoperative preparation. In brief, antiseptic showers are started 2 days before surgery, the operating theater is equipped with a laminar-flow system, local iodine antiseptic skin preparation is performed during sterile surgical draping, and antibiotic prophylaxis ( $1^{\text {st }}$ or $2^{\text {nd }}$ generation cephalosporin or vancomycin) is administered for each surgery. In long-lasting procedures, injection is repeated at 3 hours for cephalosporin but not for vancomycin. Topical vancomycin powder was not used.

Deep SSI is defined by the combination of: I) clinical criteria: fever, pain, local inflammation, wound discharge, collection; II) biological criteria: inflammatory syndrome, $\geq 2$ positive bacteriological deep (subfascial) samples; III) radiological criteria: deep collection, spondylitis. SSI are systematically managed by a multidisciplinary team including the attending surgeon, an infectious diseases specialist, a microbiologist, an anesthesiologist, and a radiologist. Initially, an early surgical debridement-irrigation is performed with spinal implants and bone graft retention if infection occurs within the 3 months after initial procedure except in case of obvious implant mobilization or implant loosening. Initial empirical antibiotic treatment includes two synergic and bactericidal molecules, replaced by a targeted therapy as soon as cultures are available and according to recommendations of an infectious disease specialist (immediate teleconsultation); these were administered intravenously for at least 2 weeks and then switched to oral drugs. This switch is left at the physician's discretion. Intravenous antimicrobials are frequently prolonged in patients infected with resistant pathogens, as well as those with polymicrobial infection to avoid a high number of daily intakes. Antimicrobials are usually maintained for a total duration of at least 3 months (with systematic infectious disease specialist consultation within the first weeks of treatment). Follow-up includes assessment of back pain, local clinical inflammatory signs, laboratory inflammatory (C-reactive protein $[\mathrm{CRP}]$, and $\mathrm{WBC}$ ) and radiological parameters (X-ray, MRI, and/or PET scan), maintained for a minimum of 2 years by the attending surgeon and/or the infectious diseases specialist [12]. In some patients, a second-look surgery is performed 2-4 days after the initial debridement surgery as part of the protocol if one (or more) of the following parameters is (are) encountered: I) extensive infectious process, II) aggressive pathogen (meticillin- resistant $S$ aureus, MRSA), III) persistence/recurrence of incision outflow after 2 days and/or IV) persistence of fever for more than 2 days.

Treatment failure is defined by the need for a new surgical revision for persistent or increasing signs of SSI beyond 7 days after the beginning of the 
DAIR protocol. Relapse is defined as reappearance of signs of infection after the end of antibiotic treatment. New SSI is defined by an SSI with a pathogen different from the one responsible for the initial infection. In absence of relapse after 1 year (no surgical revision, no clinical sign of infection, CRP $<10$ $\mathrm{mg} / \mathrm{L}$ and no radiological sign of infection), the patient is considered cured. However, the patient is systematically followed for a 2-year period. Detailed definitions of the terms used in the study are outlined in Table 1.

Inclusion criteria were age 18 years or above and presence of a deep infection after instrumented spinal fusion. Exclusion criteria were non-instrumented surgery, SSI occurring in patients with hardware not implanted for spinal stabilization (intrathecal therapy pump, CSF shunts), recent history ( $<2$ years) of deep SSI at the same surgical site, infection managed by a different protocol, removal of the spinal instrumentation at first debridement surgery, and fungal infection. Patients with follow-up shorter than one year were included for the descriptive analysis of SSI but were not part of the analysis of risk factors for treatment failure or relapse. Patient selection is

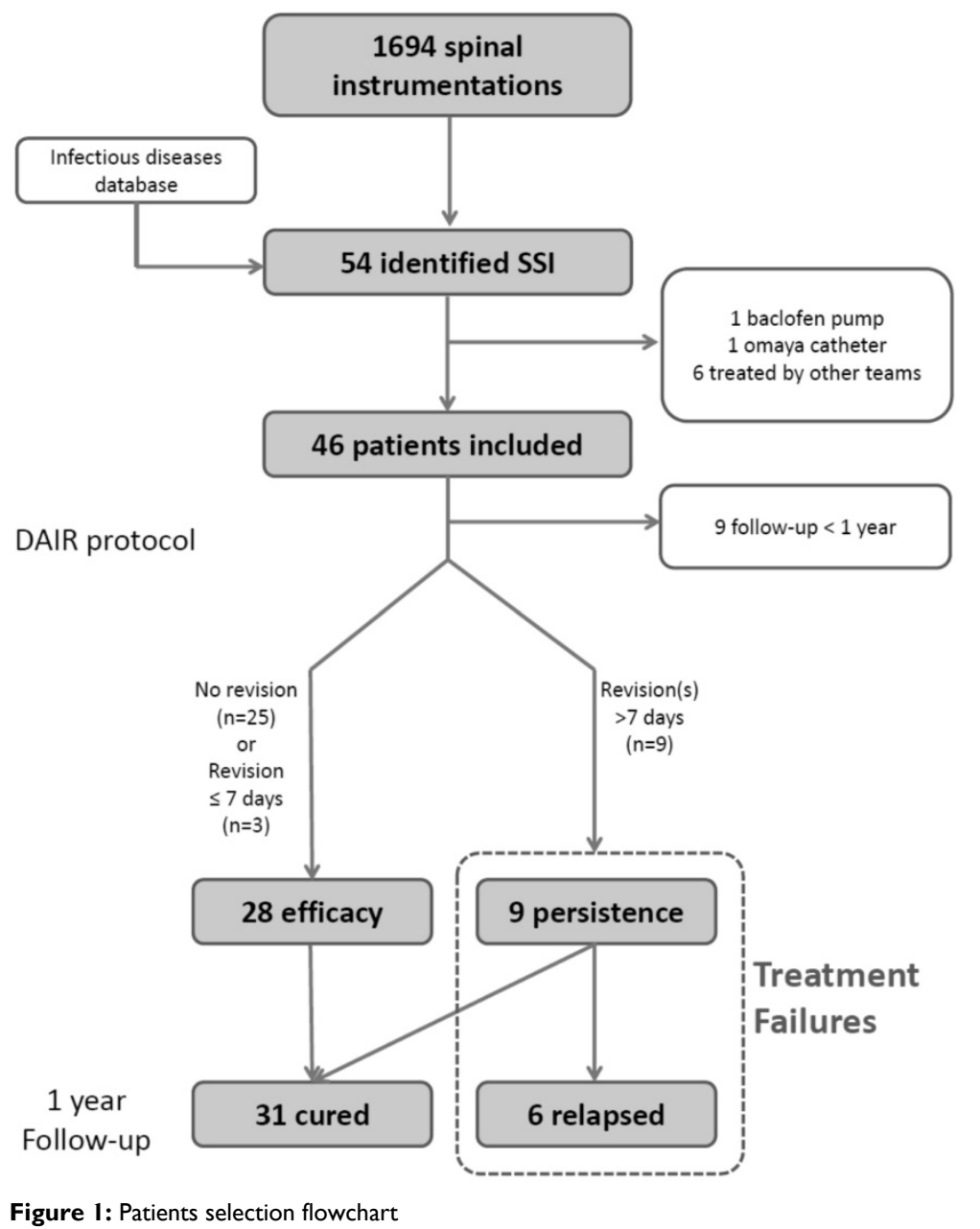

outlined in Figure 1.

Statistical analysis was performed using $R$ software ( $\mathrm{R}$ Core Team R: A language and environment for statistical computing, v 3.1.2 for Mac OSx). For the descriptive statistical analysis, the median and interquartile range (IQR) or mean and standard deviation (SD) were calculated. Thereafter, comparative analysis was performed between: I) cured group vs. relapse group; II) treatment failure vs. treatment success. Fisher's exact test was used for qualitative variables and logistic regression was used for quantitative variables.

\section{Results}

\section{Patient characteristics}

Between April 9, 2011 and October 13, 2014, a total 2268 spinal procedures were performed in 2049 patients. Eight patients with SSI were identified via the infectious diseases department database but were excluded because they were treated for other conditions $(n=2)$ or by other surgical teams, in absence of a standardized protocol (n=6; Fig. 1).

Among the 1694 surgical procedures with spinal instrumentation, deep infections occurred in $46(2.7 \%)$ patients who were included in the study. Of these, $28(61 \%)$ were men and the median age was 55 years (IQR: 40-62). Nearly two-thirds $(63 \%)$ were over-weight (BMI>25) and 26\% were obese (BMI> 30). Only $15 \%$ of the overall population had diabetes. Seven patients (15\%) had chronic pulmonary disease and $26 \%$ were active smokers. The median Modified Charlson comorbidities score was 1 (IQR: 0-3), and there was no significant difference between cured and relapse groups. A total of 9/46 patients $(20 \%)$ had a previous spine surgery and $3(7 \%)$ had been treated previously for SSI after spinal surgery; there was no significant difference between the cured and relapse groups, respectively $5 / 31(16 \%)$ vs. $2 / 6(33 \%)$ and $1 / 6(17 \%)$ vs. $2 / 31$ (6\%; Table $2)$.

In the total population, 34 (74\%) patients were treated for degenerative conditions. All patients underwent a posterior approach; among them, 10 had also an anterior approach (combined surgery). The median number of fused vertebrae was 4 (IQR: 3-6), 29 patients (63\%) received interbody cages, and 38 (83\%) an autologous bone graft. No significant difference was found between cured and relapse groups for these aspects. Thirty-three patients (72\%) 
received prophylaxis with cefuroxime, a median 13 min (IQR: 10-20) before skin incision. Twelve patients (26\%) received vancomycin because of a documented penicillin allergy a median $12 \mathrm{~min}$ (IQR: 1-25) before skin incision. In one patient, no pre-operative antibiotic prophylaxis was documented in the operative anesthetic folder. Operative time was not available in seven patients; for those with data the mean (SD) operative time was 195 (79) min. There was no significant difference between cured and relapse groups (Table 2) or between treatment failure and treatment success groups for any patient or surgical characteristics.

\section{SSI and treatment characteristics}

The median interval between index surgery and SSI diagnosis was 16 days (IQR: 10-24); there was no difference between the relapse group (median: 20 days, IQR: 16-24) and the cured group (median: 13 days, IQR: 9-23). There were 41 (89\%) cases of early SSI, 3 cases of delayed SSI [ $2(6 \%)$ in the cured group and $1(17 \%)$ in the relapse group, that occurred respectively at 51,55, and 31 days after the index surgery], and $2(4 \%)$ cases of late SSI ( 1 in the cured group and 1 among the patients lost to follow-up, that occurred respectively 187 and 194 days after the index surgery; Table 2). Thus, late SSI occurred in $0.12 \%$ of instrumented procedures.

Table 1. Definition of terms used in this study

\begin{tabular}{|c|c|}
\hline Terms & Definitions \\
\hline Deep SSI & $\begin{array}{l}\text { Clinical, biological and radiological signs of SSI } \\
\text { associated with at least } 2 \text { deep samples } \\
\text { (subfascial) of bone, tissue or fluids surrounding } \\
\text { the material, positive for the same pathogen(s) }\end{array}$ \\
\hline $\begin{array}{l}\text { Biological inflammatory } \\
\text { response }\end{array}$ & $\mathrm{CRP}>10 \mathrm{mg} / \mathrm{L}$ and $/$ or $\mathrm{WBC}>10 \mathrm{G} / \mathrm{L}$ \\
\hline Early onset infection & $\begin{array}{l}\text { SSI occurring within the } 30 \text { days after index } \\
\text { surgery }\end{array}$ \\
\hline Delayed infection & $\begin{array}{l}\text { SSI occurring between } 1 \text { and } 3 \text { months after index } \\
\text { surgery }\end{array}$ \\
\hline Late onset infection & SSI occurring after 3 months after index surgery \\
\hline Persistence & $\begin{array}{l}\text { Need for a new surgical revision because of } \\
\text { persistent or increasing signs of SSI beyond } 7 \text { days } \\
\text { after the beginning of DAIR protocol but before } \\
\text { the end of antibiotic treatment, with } \\
\text { intraoperative samples positive for the same } \\
\text { pathogen (negative cultures do not exclude this } \\
\text { diagnosis) }\end{array}$ \\
\hline Relapse & $\begin{array}{l}\text { Reappearance of signs of infection with samples } \\
\text { growing the same pathogen after the end of } \\
\text { antibiotic treatment within } 1 \text { year after initial } \\
\text { surgery }\end{array}$ \\
\hline Treatment failure & Persistence or relapse of SSI \\
\hline New infection & $\begin{array}{l}\text { New SSI with a pathogen different from the one } \\
\text { responsible for the initial infection within } 1 \text { year of } \\
\text { follow-up }\end{array}$ \\
\hline Patient cured & $\begin{array}{l}\text { Absence of relapse after } 1 \text { year (no surgical } \\
\text { revision, no clinical sign of infection, CRP }<10 \\
\text { mg/L and no radiological sign of infection), off } \\
\text { antibiotic therapy }\end{array}$ \\
\hline
\end{tabular}

SSI: Surgical site infection; CRP: C-reactive protein; WBC: White Blood Cells; DAIR: debridement-irrigation, antibiotic therapy and implant retention.
Table 2. Patient and surgical characteristics

\begin{tabular}{|c|c|c|c|c|}
\hline & $\begin{array}{l}\text { Patients } \\
\text { with SSI } \\
(\mathrm{n}=46)\end{array}$ & $\begin{array}{l}\text { Cured } \\
(n=31)\end{array}$ & $\begin{array}{l}\text { Relapse } \\
(\mathrm{n}=6)\end{array}$ & $\begin{array}{l}\text { Lost } \\
\text { FU } \\
(n=9)\end{array}$ \\
\hline \multicolumn{5}{|l|}{ Medical conditions } \\
\hline Male sex, n (\%) & $28(61)$ & $18(58)$ & $5(83)$ & $5(56)$ \\
\hline Median age, years (IQR) & $\begin{array}{l}55 \\
(40-62)\end{array}$ & $\begin{array}{l}54 \\
(44-62)\end{array}$ & $\begin{array}{l}44 \\
(33-55)\end{array}$ & $\begin{array}{l}58 \\
(39-73)\end{array}$ \\
\hline Mean BMI kg/m² (SD) & $27.2(4.9)$ & $\begin{array}{l}27.5 \\
(5.3)\end{array}$ & $\begin{array}{l}27.9 \\
(4.2)\end{array}$ & $26(4)$ \\
\hline Overweight (BMI>25kg/m²), n (\%) & $29(63)$ & $20(58)$ & $5(83)$ & $4(44)$ \\
\hline Obesity $\left(\mathrm{BMI}>30 \mathrm{~kg} / \mathrm{m}^{2}\right), \mathrm{n}(\%)$ & $12(26)$ & $7(23)$ & $3(50)$ & $2(22)$ \\
\hline Malnutrition $\left(\mathrm{BMI}<18 \mathrm{~kg} / \mathrm{m}^{2}\right), \mathrm{n}(\%)$ & $2(4)$ & $1(3)$ & 0 & 0 \\
\hline Diabetes, n (\%) & $7(15)$ & $6(19)$ & 0 & $1(11)$ \\
\hline Immunodeficiency, $\mathrm{n}(\%)$ & $2(4)$ & $2(6)$ & 0 & 0 \\
\hline Renal insufficiency, $\mathrm{n}(\%)$ & $2(4)$ & $1(3)$ & 0 & 0 \\
\hline Liver insufficiency, $\mathrm{n}(\%)$ & 0 & 0 & 0 & 0 \\
\hline Chronic pulmonary disease, $\mathrm{n}(\%)$ & $7(15)$ & $4(19)$ & $1(17)$ & $2(22)$ \\
\hline Cardiac insufficiency, $\mathrm{n}(\%)$ & $2(4)$ & $1(3)$ & 0 & $1(11)$ \\
\hline Coronaropathy, n (\%) & $2(4)$ & $1(3)$ & 0 & $1(11)$ \\
\hline Active malignancy, n (\%) & $5(11)$ & $5(16)$ & 0 & 0 \\
\hline Modified Charlson score, median (IQR) & $1(0-3)$ & $1(0-4)$ & $1(0-1)$ & $1(0-1)$ \\
\hline Active smoking, $\mathrm{n}(\%)$ & $12(26)$ & $8(26)$ & $2(33)$ & $2(22)$ \\
\hline Alcohol abuse, $\mathrm{n}(\%)$ & $2(4)$ & $2(6)$ & 0 & 0 \\
\hline Previous spine surgery, $\mathrm{n}(\%)$ & $9(20)$ & $5(16)$ & $2(33)$ & $2(22)$ \\
\hline Previous SSI after spine surgery, $\mathrm{n}(\%)$ & $3(7)$ & $2(6)$ & $1(17)$ & 0 \\
\hline \multicolumn{5}{|l|}{ Operative features (index surgery) } \\
\hline Degenerative, $\mathrm{n}(\%)$ & $34(74)$ & $23(74)$ & $4(67)$ & $7(78)$ \\
\hline Traumatic, n (\%) & $10(22)$ & $6(19)$ & $2(33)$ & $2(22)$ \\
\hline Malignancy, $\mathrm{n}(\%)$ & $2(4)$ & $2(6)$ & 0 & 0 \\
\hline DL - post, $\mathrm{n}(\%)$ & $35(76)$ & $24(77)$ & $4(33)$ & $7(78)$ \\
\hline DL - ant, n (\%) & 0 & 0 & 0 & 0 \\
\hline $\mathrm{DL}-\mathrm{comb}, \mathrm{n}(\%)$ & $9(20)$ & $6(19)$ & $2(33)$ & $1(11)$ \\
\hline Cerv - ant, n (\%) & 0 & 0 & 0 & 0 \\
\hline Cerv - post, n (\%) & $1(2)$ & $1(3)$ & 0 & 0 \\
\hline Cerv - comb, n (\%) & $1(2)$ & 0 & 0 & $1(11)$ \\
\hline Antibiotic prophylaxis, type (n) & $\begin{array}{l}\mathrm{C}(33) ; \mathrm{V} \\
(12)\end{array}$ & $\begin{array}{l}\text { C (23); } \\
\text { V (8) }\end{array}$ & $\begin{array}{l}\mathrm{C}(4) ; \mathrm{V} \\
(2)\end{array}$ & $\begin{array}{l}\text { C (6); } \\
\text { V (2) }\end{array}$ \\
\hline $\begin{array}{l}\text { Number of fused vertebrae, } \\
\text { median (IQR) }\end{array}$ & $4(3-6)$ & $4(3-6)$ & $3(2-5)$ & $6(3-7)$ \\
\hline$\leq 4$ fused vertebrae, $\mathrm{n}(\%)$ & $26(57)$ & $18(58)$ & $4(67)$ & $4(44)$ \\
\hline$>5$ fused vertebrae, $\mathrm{n}(\%)$ & $20(43)$ & $13(42)$ & $2(33)$ & $5(56)$ \\
\hline Interbody cages, n (\%) & $29(63)$ & $19(62)$ & $4(67)$ & $6(67)$ \\
\hline Bone graft, $\mathrm{n}(\%)$ & $38(83)$ & $27(87)$ & $6(100)$ & $5(56)$ \\
\hline Mean operative time, hours (SD) & $195(79)$ & $\begin{array}{l}187 \\
(81)\end{array}$ & $230(89)$ & $\begin{array}{l}214 \\
(58)\end{array}$ \\
\hline Mean intraoperative blood loss, $\mathrm{mL}$ (SD) & $922(741)$ & $\begin{array}{l}934 \\
(715)\end{array}$ & $\begin{array}{l}462 \\
(398)\end{array}$ & $\begin{array}{l}1216 \\
(1032)\end{array}$ \\
\hline
\end{tabular}

FU: Follow-up; BMI: body mass index (kg/m2); DL: dorsal-lumbar; Cerv: cervical; post: posterior; ant: anterior; comb: combined (anterior-posterior approach). Antibiotic prophylaxis: C: cephalosporin; V: vancomycin.

No significant difference was found between cured and relapse groups for any characteristic.

In the total population, $3(7 \%)$ patients had septic shock ( 2 in the cured group and 1 in the relapse group), 19 (41\%) had fever, $12(26 \%)$ had back pain, and only one $(2 \%)$ presented neurological deficit (isolated sphincter impairment). All but one (98\%) had local inflammatory wound and/or wound discharge.

The median interval between SSI diagnosis and surgical DAIR management was 3 days (IQR: 2-5) days. Deep samples (subfascial) were positive in all patients. Staphylococcus aureus was the most frequently isolated strain (59\%); there was only one case of MRSA. Polymicrobial SSI were uncommon $(24 \%)$ as 
were resistant strains (17\%). Bone samples were collected in less than a third of patients $(30 \%)$; among these, only one third $(5 / 14,36 \%)$ were positive (all with the same pathogen as that found in the deep surgical sample). Blood cultures were collected from 18 patients (39\%); all $13(72 \%)$ positive cultures found concordant pathogens between superficial and deep specimens. Blood cultures were positive in all relapse patients and in $54 \%$ in the cured group. Statistical analysis found no difference between cured and relapse groups (Table 3) or between treatment failure and treatment success groups for any SSI characteristics.

Table 3. SSI and treatment characteristics

\begin{tabular}{|c|c|c|c|c|}
\hline & $\begin{array}{l}\text { Patients } \\
\text { with SSI } \\
(\mathrm{n}=46)\end{array}$ & $\begin{array}{l}\text { Cured } \\
(n=31)\end{array}$ & $\begin{array}{l}\text { Relapse } \\
(n=6)\end{array}$ & $\begin{array}{l}\text { Lost } \\
\text { FU } \\
(n=9)\end{array}$ \\
\hline \multicolumn{5}{|l|}{ Timing } \\
\hline $\begin{array}{l}\text { Median interval between index } \\
\text { surgery and SSI, days (IQR) }\end{array}$ & $17(10-24)$ & $16(10-35)$ & $\begin{array}{l}23 \\
(17-24)\end{array}$ & $\begin{array}{l}18 \\
(11-20)\end{array}$ \\
\hline Early SSI, n (\%) & $41(89)$ & $27(87)$ & $5(83)$ & $8(89)$ \\
\hline Delayed SSI, n (\%) & $3(7)$ & $2(6)$ & $1(17)$ & 0 \\
\hline Late SSI, n (\%) & $2(4)$ & $1(3)$ & 0 & $1(11)$ \\
\hline $\begin{array}{l}\text { Median interval between SSI } \\
\text { and DAIR, days (IQR) }\end{array}$ & $3(2-5)$ & $3(2-5)$ & $2(2-4)$ & $2(2-3)$ \\
\hline \multicolumn{5}{|l|}{ Biological inflammatory markers } \\
\hline $\begin{array}{l}\text { Mean CRP at diagnosis, } \mathrm{mg} / \mathrm{L} \\
\text { (SD), }\end{array}$ & $\begin{array}{l}149.2 \\
(120.1)\end{array}$ & $\begin{array}{l}176.2 \\
(124)\end{array}$ & $\begin{array}{l}91.1 \\
(79.3)\end{array}$ & $98(107)$ \\
\hline $\begin{array}{l}\text { Mean maximum CRP, mg/L } \\
\text { (SD) }\end{array}$ & $\begin{array}{l}160.7 \\
(99.3)\end{array}$ & $\begin{array}{l}177.5 \\
(98.2)\end{array}$ & $\begin{array}{l}148.2 \\
(98.4)\end{array}$ & $\begin{array}{l}113 \\
(97.2)\end{array}$ \\
\hline $\begin{array}{l}\text { Mean WBC at diagnosis, G/L } \\
\text { (SD) }\end{array}$ & $10.9(4.2)$ & $11.2(4.3)$ & $\begin{array}{l}10.1 \\
(2.7)\end{array}$ & $\begin{array}{l}10.3 \\
(4.9)\end{array}$ \\
\hline $\begin{array}{l}\text { Mean maximum WBC, G/L } \\
\text { (SD) }\end{array}$ & $11.8(4.2)$ & $11.8(4.4)$ & $\begin{array}{l}10.6 \\
(2.5)\end{array}$ & $\begin{array}{l}12.7 \\
(4.8)\end{array}$ \\
\hline \multicolumn{5}{|l|}{ Microbiological characteristics } \\
\hline Positive deep samples, n (\%) & $46(100)$ & $31(100)$ & $6(100)$ & $9(100)$ \\
\hline$S$ aureus, $\mathrm{n}(\%)$ & $27(59)$ & $16(52)$ & $4(67)$ & $7(78)$ \\
\hline Enterobacteria, n (\%) & $15(33)$ & $14(45)$ & 0 & $1(11)$ \\
\hline Enterococcus, n (\%) & $3(6)$ & $2(6)$ & $1(17)$ & 0 \\
\hline Pseudomonas aeruginosa, n (\%) & $5(11)$ & $5(16)$ & 0 & 0 \\
\hline CoNS, n (\%) & $6(13)$ & $3(10)$ & $1(17)$ & $2(22)$ \\
\hline Propionibacterium acnes, $\mathrm{n}(\%)$ & $4(9)$ & $3(10)$ & 0 & $1(14)$ \\
\hline Polymicrobial, n (\%) & $11(24)$ & $9(29)$ & $1(17)$ & $2(22)$ \\
\hline Resistant strains, n (\%) & $8(17)$ & $3(10)$ & $1(17)$ & $4(44)$ \\
\hline Bone sample, $\mathrm{n}(\%)$ & $14(30)$ & $9(29)$ & $2(33)$ & $3(33)$ \\
\hline $\begin{array}{l}\text { Positive bone sample, } \\
\mathrm{n}(\% \text { of bone sample })\end{array}$ & $5(36)$ & $8(89)$ & $2(100)$ & $3(100)$ \\
\hline Blood culture, n (\%) & $18(39)$ & $13(42)$ & $2(33)$ & $2(22)$ \\
\hline $\begin{array}{l}\text { Positive blood culture, } \\
\mathrm{n}(\% \text { of blood culture })\end{array}$ & $13(72)$ & $7(54)$ & $2(100)$ & $2(100)$ \\
\hline \multicolumn{5}{|l|}{ Treatment characteristics } \\
\hline Early treatment failure, n (\%) & $2(4)$ & $2(6)$ & 0 & - \\
\hline Delayed treatment failure, n (\%) & $11(24)$ & $4(13)$ & $6(100)$ & - \\
\hline $\begin{array}{l}\text { Median total duration of } \\
\text { antibiotic treatment, months } \\
\text { (IQR) }\end{array}$ & $6(3-9)$ & $6(3-8)$ & $9(6-12)$ & - \\
\hline $\begin{array}{l}\text { Median total duration of } \\
\text { follow-up, months (IQR) }\end{array}$ & $20(14-27)$ & $20(15-27)$ & $\begin{array}{l}19 \\
(11-30)\end{array}$ & - \\
\hline
\end{tabular}

FU: Follow-up. CRP: C-reactive protein; WBC: white blood cells; $\mathrm{S}$ aureus: Staphylococcus aureus; Enterobacteria: Escherichia coli, Proteus mirabilis, Klebsiella pneumoniae, Salmonella enteridis, Enterobacter cloacae, Citrobacter freundii; Enterococcus: E. faecalis, E. faecium; CoNS: coagulase negative staphylococci including S. epidermidis, S. Capitis, S. Warneri. Polymicrobial: SSI with two or more pathogens. Resistant strains: bacteria presenting resistance to classically active antibiotics. No significant difference were found between cured and relapse groups for any characteristic.

\section{Therapeutic management and outcomes}

All patients were managed by a multidisciplinary team and treated using the DAIR protocol in the initial phase of SSI. Overall, the application of DAIR protocol was associated with a $84 \%$ success rate.

In patients with at least 1 year of follow up $(\mathrm{n}=37)$, treatment failure occurred in 9 patients $(24 \%)$; among them, 6 underwent a late (beyond 7 days after first debridement surgery) iterative debridement surgery, 2 underwent 2 iterative debridement surgeries, and 1 underwent 4 iterative debridement surgeries. Three of these 9 patients recovered and were cured at 1 year of follow-up. Relapse occurred in the 6 others. Figure 2 presents treatment failure-free survival of the population with 1 year follow-up.

Among the total population, instrumentation was removed in only 2 patients (4\%); both were cases of early SSI. For these, treatment failure occurred very late; at 115 and 191 days after the beginning of treatment. One patient relapsed and 1 patient was cured at 1 year.

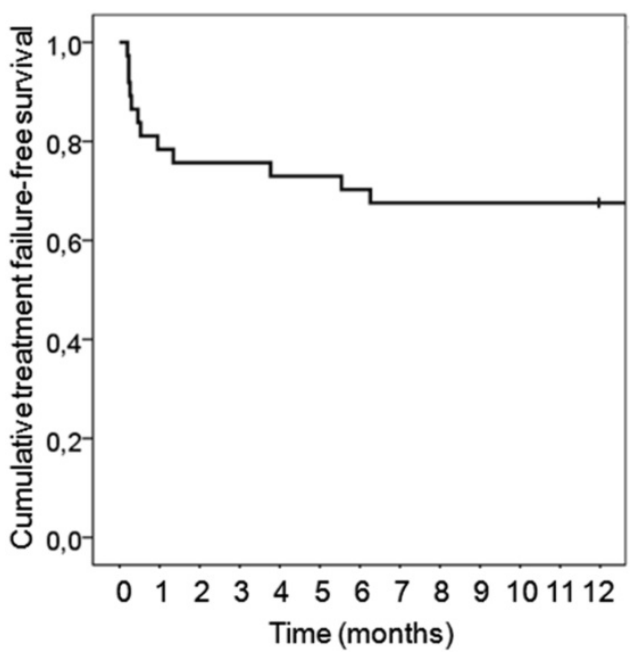

Figure 2: Treatment failure-free survival rate.

All patients received a combination therapy during the 2-week initial phase; antibiotics were administered intravenously (IV) except fluoroquinolones and rifampicin that were given orally. Vancomycin and fluoroquinolones were the most frequently used antibiotics, respectively in $46 \%$ and $37 \%$ patients; aminoglycosides were administrated in only 8 patients $(17 \%)$ during the initial phase. During the second phase a combination therapy (including rifampicin) was used to treat patients with $S$ aureus infections, and monotherapy was used for those infected with other strains; the total duration was 3-6 months. Antibiotics were interrupted by the infectious diseases specialist in all cases when patients had no clinical signs of ongoing infection, CRP was 
normalized $(<10 \mathrm{mg} / \mathrm{L})$, and radiological features (including PET scan for 26 patients) were considered normal. The median duration of antibiotics was 6 months (IQR: 3-9; Table 3).

The infectious specialist managed the choice of antibiotic therapy as soon as cultures were available. The median time between the start of SSI management and infectious specialist consultation was 3 weeks (IQR: $2-4)$. Nine patients (20\%) were lost to follow-up before 1 year. Among the 37 patients who had a follow-up $\geq 12$ months, the median duration of follow-up (infectious specialist and/or spine surgeon) was 20 months (IQR: 14-27), with median duration of follow-up after completion of antibiotic therapy of 13 months (IQR: 9-20). The minimum duration of follow-up after the end of antibiotic treatment was 6 months (this concerned 6 patients).

\section{Discussion}

This study describes the outcomes of 46 patients treated for deep surgical site infections after instrumented spine surgery and according to a protocol including surgical debridement-irrigation, antibiotic therapy and implant retention.

The incidence of SSI was $2.7 \%$, and is in line with that reported elsewhere [9,10,13-17]. Most of the cases (89\%) were early SSI (occurring within the first months after the index surgery). The frequency of late SSI (occurring after 3 months) was only $0.12 \%$, which is lower than the rates of 1.7 and $2.7 \%$ previously reported [2].

The main result of this study is that the application of DAIR protocol was associated with a successful outcome in $31 / 37$ patients $(84 \%)$ including two delayed SSI and one late SSI. This result is in line with the previous publications reporting treatment of SSI after spinal instrumentation with the DAIR protocol. For instance, in a retrospective cohort study of 81 deep SSI, 22/23 patients (96\%) with early-onset SSI and 13/51 (25\%) with late-onset SSI were treated with DAIR; the 2-year treatment failure-free survival was $80 \%$ for patients receiving DAIR followed by oral antimicrobial suppression therapy, but only $33 \%$ if no antimicrobial suppression therapy was administered [10]. In another retrospective cohort study of 50 deep early-onset and delayed SSI, $88 \%$ of the patients were cured and free of treatment 2 years after surgery [9]. Furthermore, in the largest retrospective cohort study conducted on the subject, which included 129 patients treated for early and delayed SSI, success rate of DAIR was $82 \%$ [17].

In some circumstances, it is assumed that only 1 debridement surgery may be not sufficient. Therefore, in order to increase the chance of success, based on our experience and supported by the present study, we recommend a "second look" surgery 2-4 days after the initial debridement surgery if one (or more) of the following parameters is (are) encountered: I) extensive infectious process, II) aggressive pathogen (MRSA), III) persistence/recurrence of wound discharge after 2 days, and/or IV) persistence of fever after 2 days. The prevalence of MRSA, a pathogen known to increase the risk of treatment failure, was surprisingly low in the present study.

As reported elsewhere [9, 17], we did not identify any statistically significant risk factors for treatment failure or relapse, but it should be noted that the study was underpowered to find such differences. Thus, no clear selection criteria can be proposed to identify patients who would most benefit from the DAIR protocol; the only constraint is a short interval (1-3 months) between index surgery and SSI diagnosis. DAIR protocol should be considered for early-onset and delayed SSI as the success rate is greater than $80 \%$. Use of the DAIR protocol in late-onset SSI seems more hazardous. Herein only 2 such patients were treated with the DAIR protocol; 1 was cured and the other was lost to follow-up, precluding any conclusion in this regard. In the only study with a sufficiently large number of late-onset SSI treated with DAIR $(n=25)$, the 2-year treatment failure-free survival was only $36 \%$ [10]. Thus, in late-onset SSI, removal of instrumentation should be preferred. Moreover, given the very high (67\%) relapse rates among patients with a persistent SSI, this population may benefit from long-term antibiotic suppression.

In the present study population the following characteristics, traditionally considered as risk factors for SSI after spinal surgery, were in line with other publications: nearly two-thirds were over-weight; over a quarter were obese, nearly half had a long operative time ( $\geq 3$ hours), in nearly all a posterior dorsal-lumbar approach was used, vertebrae were fused was used in the overwhelming majority of patients, and the number of fused vertebrae was high in many patients (nearly half had five or more fused vertebrae). However, other known risks factors were relatively uncommon: only a minority had diabetes mellitus and only a quarter were active smokers. Other large series concerning SSI after instrumented spine surgery also reported low rates of diabetes mellitus (10.4 to $14 \%$ ) and active smokers (28.9\%-33\%) $[9,13,17]$. Thus, if diabetes and active smoking are recognized risk factors for joint arthroplasty [18], there is weak evidence to consider them as risk factors for SSI after spine instrumentation. However, as we did not compare the SSI population to uninfected patients for these factors, we cannot conclude whether 
or not they are risk factors. The development of preoperative predictive models for major complications following spine surgery could allow physicians to evaluate precisely personal risk for each patient [19].

Prophylactic antibiotics are suggested to decrease the rate of SSI after instrumented and uninstrumented spinal surgery [4], and recommended by all learned societies, including the North American Spine Society (NASS) [20] and the French society of anesthesiology and intensive care (SFAR) [21]. No drug, dose, or route of administration has clearly been demonstrated to be superior [4]. However, cefazolin is recommended as the first choice for instrumented spine procedures. Routine use of second- and third-generation cephalosporins is classically not recommended, in part due to the promotion of resistance particularly among healthcare-associated Gram-negative bacilli [21]. In the present study, the first choice for prophylaxis was a second generation cephalosporin (cefuroxime) most due to local prevalence of gram-negative bacteria in this population; in particular enterobacteria was the second cause of SSI in our institution. It is of note that the incidence of resistant strains herein was lower than reported elsewhere (40\%) [9].

The present study has several limitations. The small number of patients limited the statistical analysis and we were unable to identify any risk factors for treatment failure or relapse in patients with SSI treated according to the DAIR protocol. Moreover, the high number of patients lost to follow-up limited the estimation of the success rate of the DAIR protocol. The limited duration of follow-up after antibiotic therapy completion in some patients could also have biased the outcome.

\section{Conclusions}

In conclusion, the present study supports the effectiveness of debridement-irrigation surgery, antibiotic therapy, and implant retention in surgical site infections occurring within the 3 months after instrumented spinal surgery. Studies performed on larger populations could help to enhance the selection of patients for such protocol and confirm the usefulness of early second look surgery.

\section{Competing Interests}

The authors have declared that no competing interest exists.

\section{References}

1. Fei Q, Li J, Lin J, Li D, Wang B, Meng H, et al. Risk Factors for Surgical Site Infection After Spinal Surgery: A Meta-Analysis. World Neurosurg. 2016; 95 : 507-15.
2. Nasser R, Yadla S, Maltenfort MG, Harrop JS, Anderson DG, Vaccaro AR, et al. Complications in spine surgery. J Neurosurg Spine. 2010; 13: 144-57.

3. Subramanyam R, Schaffzin J, Cudilo EM, Rao MB, Varughese AM. Systematic review of risk factors for surgical site infection in pediatric scoliosis surgery. Spine J Off J North Am Spine Soc. 2015; 15: 1422-31.

4. Shaffer WO, Baisden JL, Fernand R, Matz PG, North American Spine Society. An evidence-based clinical guideline for antibiotic prophylaxis in spine surgery. Spine J Off J North Am Spine Soc. 2013; 13: 1387-92

5. Ferry T, Valour F, Lustig S, Laurent F, Perrin G, Chidiac C, et al. The challenge of infection prevention in spine surgery: an update. Eur J Orthop Surg Traumatol Orthop Traumatol. 2013; 23 Suppl 1: S15-19.

6. Sierra-Hoffman M, Jinadatha C, Carpenter JL, Rahm M. Postoperative instrumented spine infections: a retrospective review. South Med J. 2010; 103: 25-30.

7. Wiley AM, Trueta J. The vascular anatomy of the spine and its relationship to pyogenic vertebral osteomyelitis. J Bone Joint Surg Br. 1959; 41: 796-809.

8. Osmon DR, Berbari EF, Berendt AR, Lew D, Zimmerli W, Steckelberg JM, et al. Diagnosis and management of prosthetic joint infection: clinical practice guidelines by the Infectious Diseases Society of America. Clin Infect Dis Off Publ Infect Dis Soc Am. 2013; 56: e1-25.

9. Dubée V, Lenoir T, Leflon-Guibout V, Briere-Bellier C, Guigui P, Fantin B. Three-month antibiotic therapy for early-onset postoperative spinal implant infections. Clin Infect Dis Off Publ Infect Dis Soc Am. 2012; 55: 1481-7.

10. Kowalski TJ, Berbari EF, Huddleston PM, Steckelberg JM, Mandrekar JN, Osmon DR. The management and outcome of spinal implant infections: contemporary retrospective cohort study. Clin Infect Dis Off Publ Infect Dis Soc Am. 2007; 44: 913-20.

11. [Internet] Centre de référence des infections ostéo-articulaires complexes. Revised 10th jully 2018. http://www.crioac-lyon.fr

12. Barrey C, Launay O, Freitas E, Michel F, Laurent F, Chidiac C, et al. The follow-up of patients with postoperative infection of the spine. Eur J Orthop Surg Traumatol Orthop Traumatol. 2013; 23 Suppl 1: S29-34

13. Fang A, Hu SS, Endres N, Bradford DS. Risk factors for infection after spinal surgery. Spine. 2005; 30: 1460-5.

14. Glassman SD, Dimar JR, Puno RM, Johnson JR. Salvage of instrumental lumbar fusions complicated by surgical wound infection. Spine. 1996; 21: 2163-9.

15. Pull ter Gunne AF, Hosman AJF, Cohen DB, Schuetz M, Habil D, van Laarhoven CJHM, et al. A methodological systematic review on surgical site infections following spinal surgery: part 1: risk factors. Spine. 2012; 37: 2017-33.

16. Schimmel JJP, Horsting PP, de Kleuver M, Wonders G, van Limbeek J. Risk factors for deep surgical site infections after spinal fusion. Eur Spine J Off Publ Eur Spine Soc Eur Spinal Deform Soc Eur Sect Cerv Spine Res Soc. 2010; 19: $1711-9$

17. Wille H, Dauchy F-A, Desclaux A, Dutronc H, Vareil M-O, Dubois V, et al. Efficacy of debridement, antibiotic therapy and implant retention within three months during postoperative instrumented spine infections. Infect Dis Lond Engl. 2017; 49: 261-7.

18. Della Valle C, Parvizi J, Bauer TW, Dicesare PE, Evans RP, Segreti J, et al. Diagnosis of periprosthetic joint infections of the hip and knee. J Am Acad Orthop Surg. 2010; 18: 760-70.

19. Scheer JK, Smith JS, Schwab F, Lafage V, Shaffrey CI, Bess S, et al. Development of a preoperative predictive model for major complications following adult spinal deformity surgery. J Neurosurg Spine. 2017; 26: 736-43.

20. Bratzler DW, Dellinger EP, Olsen KM, Perl TM, Auwaerter PG, Bolon MK, et al. Clinical practice guidelines for antimicrobial prophylaxis in surgery. Am J Health-Syst Pharm AJHP Off J Am Soc Health-Syst Pharm. 2013; 70: 195-283.

21. [Internet] Recommandations Formalisées d'Experts. SFAR. Antibioprophylaxie en chirurgie et médecine interventionnelle (patients adultes). Revised 2017. http://sfar.org/wp-content/uploads/2017/09/Antibioprophylaxieversion-2017-CRC_CA_MODIF.pdf 